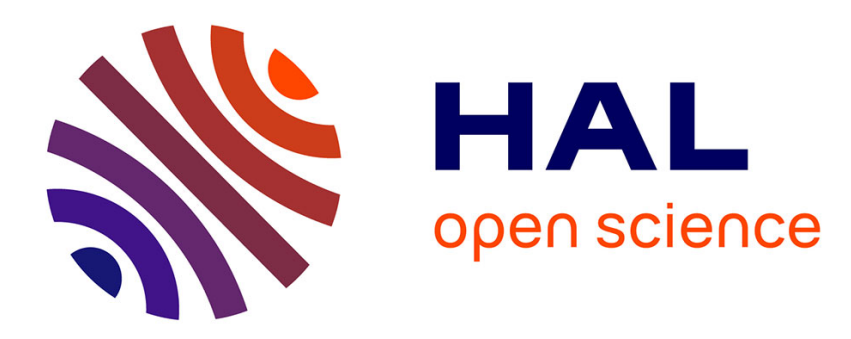

\title{
Electronic properties of Al-SiO2-(n or p) Si MIS tunnel diodes
}

\author{
J. Vuillod, G. Pananakakis
}

\section{To cite this version:}

J. Vuillod, G. Pananakakis. Electronic properties of Al-SiO2-(n or p) Si MIS tunnel diodes. Revue de Physique Appliquée, 1985, 20 (1), pp.37-44. 10.1051/rphysap:0198500200103700 . jpa-00245301

\section{HAL Id: jpa-00245301 https://hal.science/jpa-00245301}

Submitted on 1 Jan 1985

HAL is a multi-disciplinary open access archive for the deposit and dissemination of scientific research documents, whether they are published or not. The documents may come from teaching and research institutions in France or abroad, or from public or private research centers.
L'archive ouverte pluridisciplinaire HAL, est destinée au dépôt et à la diffusion de documents scientifiques de niveau recherche, publiés ou non, émanant des établissements d'enseignement et de recherche français ou étrangers, des laboratoires publics ou privés. 


\title{
Electronic properties of $\mathrm{Al}_{-} \mathrm{SiO}_{2}-(\mathrm{n}$ or $\mathbf{p})$ Si MIS tunnel diodes $\left(^{+}\right)$
}

\author{
J. Vuillod and G. Pananakakis \\ LPCS (UA-CNRS 840), INPG-ENSERG, 23, av. des Martyrs, 38031 Grenoble Cedex, France
}

(Reçu le 16 mai 1984, révisé le 18 septembre 1984, accepté le 1 ${ }^{\mathrm{er}}$ octobre 1984)

\begin{abstract}
Résumé. - Des mesures automatiques $I-V, C / G(V, \omega)$ sont utilisées pour étudier les propriétés électriques d'un grand nombre de diodes MIS tunnel $\mathrm{Al}_{-} \mathrm{SiO}_{2}-(\mathrm{n}$ ou p) $\mathrm{Si}$ avec une épaisseur d'oxyde de $30 \AA \AA$ fabriquées selon les procédés $\mathrm{LPO}_{2}$ et LPCVD. Une comparaison entre les caractéristiques $I-V$ et $C-V$ de dispositifs sur substrats $n$ et $p$ est effectuée ainsi qu'une étude de dispersion des caractéristiques $I-V$. La modélisation des caractéristiques $I-V$ a été effectuée grâce à un modèle de simulation avec deux niveaux d'états d'interface. La variation des principaux paramètres de la modélisation est corrélée avec la variation des caractéristiques $I-V$ due à la dispersion. Les densités d'états d'interface déduites de la modélisation sont en bon accord avec les valeurs obtenues à partir des mesures $C / G(V, \omega)$.
\end{abstract}

\begin{abstract}
Automatic measurements $I-V, C / G(V, \omega)$ are used to study the electrical properties of a great number of aluminum- $\mathrm{SiO}_{2}$-n or $\mathrm{p}$ type silicon MIS tunnel diodes with an oxide thickness of $30 \AA$ prepared by two technologies of oxidation, low pressure chemical vapour deposition (LPCVD) and low oxygen pressure $\left(\mathrm{LPO}_{2}\right)$. A comparison between the $I-V$ and $C-V$ characteristics on $\mathrm{n}$ and $\mathrm{p}$ substrate is presented as well as a dispersion study of $I-V$ characteristics. The modelling of $I-V$ characteristics has been carried out with a simulation model with two single level interface states. The variation of the main parameters of the modelling is connected with the variation of $I-V$ curves provoked by the dispersion. The interface state densities deduced of the modelling are in agreement with those obtained from the $C / G(V, \omega)$ measurements.
\end{abstract}

Notation.

$C_{\mathrm{m}} \quad$ measured parallel capacitance

$C_{\mathrm{p}} \quad$ (parallel) sum of space charge capacitance and interface state capacitance

$C_{\mathrm{p}}^{\prime} \quad$ parallel interface state capacitance

$C_{\mathrm{ox}} \quad$ oxide capacitance

$C_{\mathrm{sc}} \quad$ silicon space charge capacitance

$E_{\mathrm{T}} \quad$ energy of interface states in silicon band-gap

$f \quad$ signal frequency

$G_{\mathrm{m}} \quad$ measured parallel conductance

$G_{\mathrm{p}} \quad$ parallel interface state conductance

$G_{\mathrm{T}} \quad$ tunnelling conductance

I current

$J \quad$ total current density

$n \quad$ ideality factor

$N_{\mathrm{A}}, N_{\mathrm{D}}$ acceptor, donor densities in silicon

$N_{\mathrm{s}_{0}} \quad$ interface state densities of acceptor level located at $E_{\mathrm{T}_{0}}$ below the conduction band

$N_{\mathrm{s}_{1}} \quad$ interface state densities of donor level located at $E_{\mathrm{T}_{1}}$ below the conduction band

$N_{\text {ss }} \quad$ interface state density

$\left({ }^{+}\right)$Communication présentée aux Journées du G.C.I.S., Toulouse les 15 et 16 décembre 1983.
$R_{\mathrm{s}} \quad$ series-resistance

$V_{\mathrm{a}} \quad$ applied d.c. bias

$V_{\mathrm{s}} \quad$ surface potential in silicon

$V_{\mathrm{s}_{0}} \quad$ surface potential in silicon at zero bias

$\delta$ oxide thickness

$\Phi_{\text {B }} \quad$ barrier height of metal-semiconductor barrier

$\chi_{\mathrm{n}}, \chi_{\mathrm{p}} \quad$ effective electron, hole affinities

$\omega$ angular frequency

\section{Introduction.}

There is a practical interest in the study of conducting Metal-(Ultra-thin $\mathrm{SiO}_{2}$ ) Insulating-(Si) Semiconductor structures generally called MIS tunnel diodes because of their uses in microelectronics (VLSI, memory devices, photodiodes arrays) and in photocells applications.

There is also a fundamental interest in these studies because these very thin silicon oxide layers ( $30 \AA$ here) on silicon represent the initial stage of silicon oxidation.

In this paper current-voltage characteristics on $n$ and $p$ type silicon substrate are presented as well as capacitance and conductance characteristics. 
Using a self consistent numerical model of the working of MIS tunnel diodes developed by the authors $[1,2]$ the dispersion of the current-voltage characteristics of diodes on the same wafer are studied and analysed.

This work based on fully automatic experimental apparatus controlled by microcomputers, allows us to deduce extreme dispersion values of the most important physical parameters at the $\mathrm{Si}-\mathrm{SiO}_{2}$ interface : electronic affinity, oxide thickness, density and energy location of interface states.

Besides comparison between current-voltage and capacitance, conductance-voltage characteristics permits to complete and confirm the previous results.

\section{Technological characteristics of the samples.}

The devices have been fabricated in EFCIS/Thomson laboratories on $\langle 100\rangle$ oriented $n$ type and $\mathrm{p}$ type silicon substrate $\left(N_{\mathrm{D}}\right.$ or $\left.N_{\mathrm{A}}=10^{15} \mathrm{~cm}^{-3}\right)$ by two technological processes described elsewhere [1] to obtain oxide films of $30 \AA$ thickness, measured by ellipsometry :

- Thermal oxidation under low oxygen pressure at $950^{\circ} \mathrm{C}$ called $\mathrm{LPO}_{2}$.

- Low pressure chemical vapour deposition of $\mathrm{SiO}_{2}$ at $880^{\circ} \mathrm{C}$ called LPCVD.

Eight kinds of structures have been studied : LPCVD and $\mathrm{LPO}_{2}$ oxides on $\mathrm{n}$ and $\mathrm{p}$ type substrate without and with thermal annealing at $400{ }^{\circ} \mathrm{C}$ during 30 min under $\mathrm{N}_{2}$ atmosphere. A great number of tunnel diodes have been tested (the total number of devices tested is about 50 ) by using evaporated aluminum electrodes typically of $400 \mu \mathrm{m} \times 400 \mu \mathrm{m}$ on the top surface, wires are attached by ultrasonic bonding on these metallizations. Back contacts are gold or silver. No one measurement has been carried out by pressure and point contact. A special mask is used to permit the realization of the connections, which are made on thick oxide layer parts (Fig. 1).

\section{Apparatus of measurement.}

In this work automatic data acquisition is always performed. It permits the study of a great number of devices quickly, the storage of data on floppy disks for further treatments and calculations. The following measurement apparatus have been used :

- $I(V)$ measurement unit (automatic HP4140B pA meter-DC voltage source) connected through the IEEE bus-line cable to a HP9826 computer and a HP2673A graphics printer.

- $C(V), G(V)$ measurement unit described elsewhere [3] including principally :

an automatic Brookdeal lock-in amplifier with an IEEE interface connected to an Apple II computer, a preamplifier, a Boonton precision decade capacitor and a HP plotter.

- Automatic semiconductor component test sys-

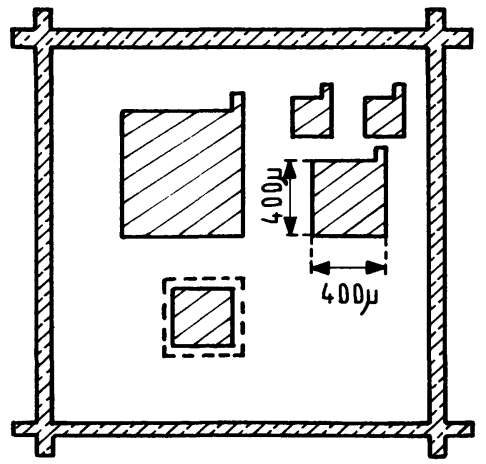

Fig. 1. - Schematic of the elementary pattern of the metallic engravure.

tem (HP4061A) consisting of a 4275A multifrequency LCR meter for AC impedance measurements from $10 \mathrm{kHz}$ to $10 \mathrm{MHz}$, a $4140 \mathrm{~A}$ pA meter-DC voltage source, a switching subsystem, a $9826 \mathrm{~A}$ controller and a 7470A plotter. This system permits among others : $I-V, C-V$ quasi-static, doping profile measurement and gives bias and/or frequency characteristics of devices.

\section{Current voltage characteristics.}

Typical current-voltage $I-V_{\mathrm{a}}$ and current density voltage $J-V_{\mathrm{a}}$ characteristics in linear and semilogarithmic plots are shown respectively in figure 2 for the eight kinds of MIS tunnel diodes mentioned in section 2. All measurements are made in the dark.

4.1 Characteristics ON n TYPE SUbSTRATE. - Typical characteristics are represented in linear (range of $10^{-8}$ or $10^{-9} \mathrm{~A}$ ) and semilogarithmic plots in figures $2 a$ and $b$ respectively. The reverse curves present a saturation current, the density is of the order of $10^{-4}$ to $10^{-2} \mathrm{~mA} / \mathrm{cm}^{2}$ (Fig. $2 \mathrm{~b}$ ).

The reverse characteristics show sometimes a " threshold effect » particularly for devices without annealing (curve 2 in Fig. 2a) : the current is first very low and then remains constant for bias lower than $-0.3 \mathrm{~V}$. The authors have explained this effect in a previous paper by introducing electrostatically acting donor-like interface states in the vicinity or below of the semiconductor midgap [1]. For the forward characteristics it may be observed that an exponential law is not generally obtained, the characteristics in semilog plot are curved towards the voltage axis. Sometimes other shapes may be observed (curve 1 in Fig. 2b), first the characteristics are slightly curved towards the voltage axis and then above $0.3 \mathrm{~V}$ the current increase more rapidly.

It may be noted also that there is a tendency to obtain larger ideality factors for non annealed samples (curves 2 and $2^{\prime}$ in Fig. 2b).

The figure 3 shows the dispersion of $J-V_{\mathrm{a}}$ characteristics of devices obtained on the same wafer in the 


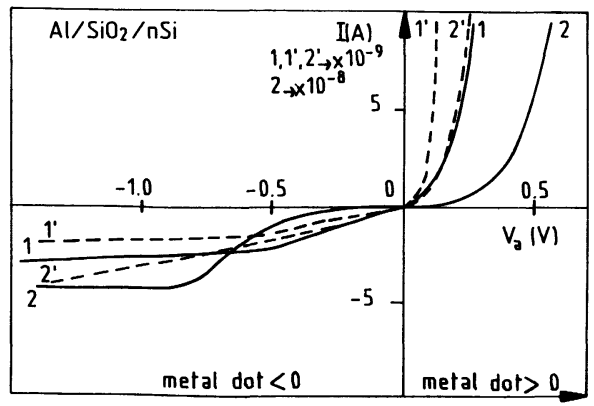

(a)

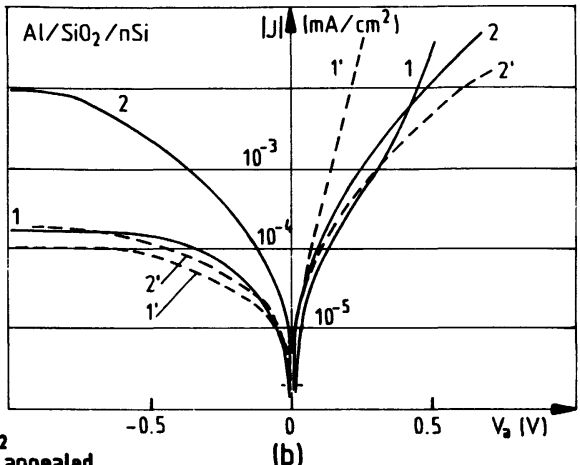

(b)

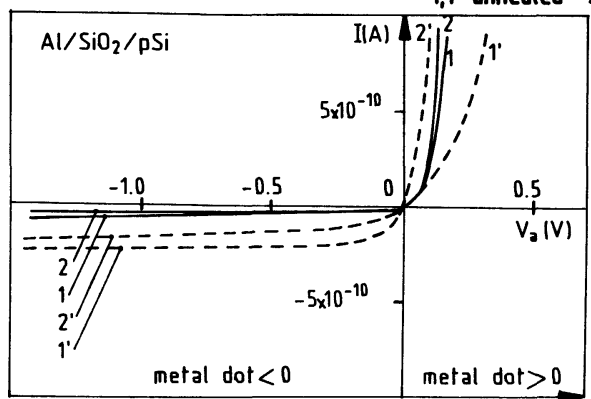

(c)

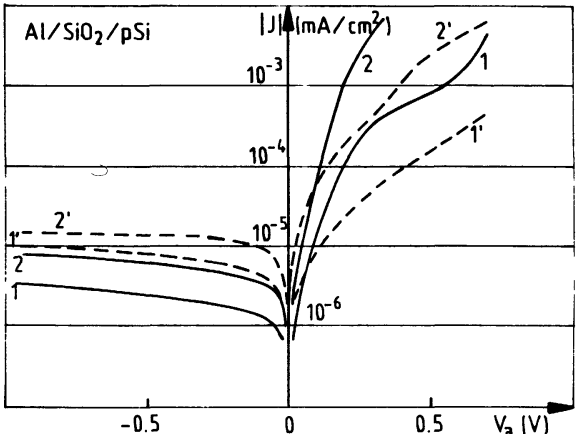

(d)

Fig. 2. - Experimental current-voltage characteristics for LPCVD (solid lines) and $\mathrm{LPO}_{2}$ (dashed lines) $\mathrm{Al}-\mathrm{SiO} \mathrm{O}_{2}-\mathrm{Si}$ diodes on $\mathrm{n}\left(\mathrm{a}\right.$ and $\mathrm{b}$ ) and $\mathrm{p}$ type wafer (c and d) annealed (curves 1) or not (curves 2). For $\mathrm{n}$ type devices $V_{\mathrm{a}}=V_{\mathrm{m}}-V_{\mathrm{sc}}$ whereas for $\mathrm{p}$ type devices $V_{\mathrm{a}}=V_{\mathrm{sc}}-V_{\mathrm{m}}$, so that the curves have familiar shapes for both $\mathrm{n}$ and $\mathrm{p}$ type wafer $\left(V_{\mathrm{m}}, V_{\mathrm{sc}}\right.$ bias to metal and to semiconductor respectively).
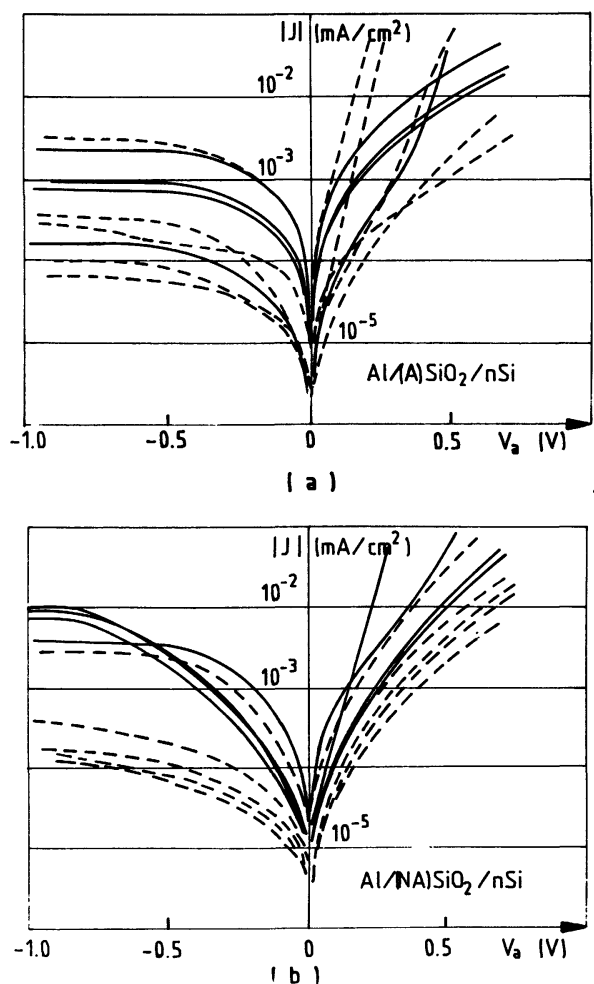
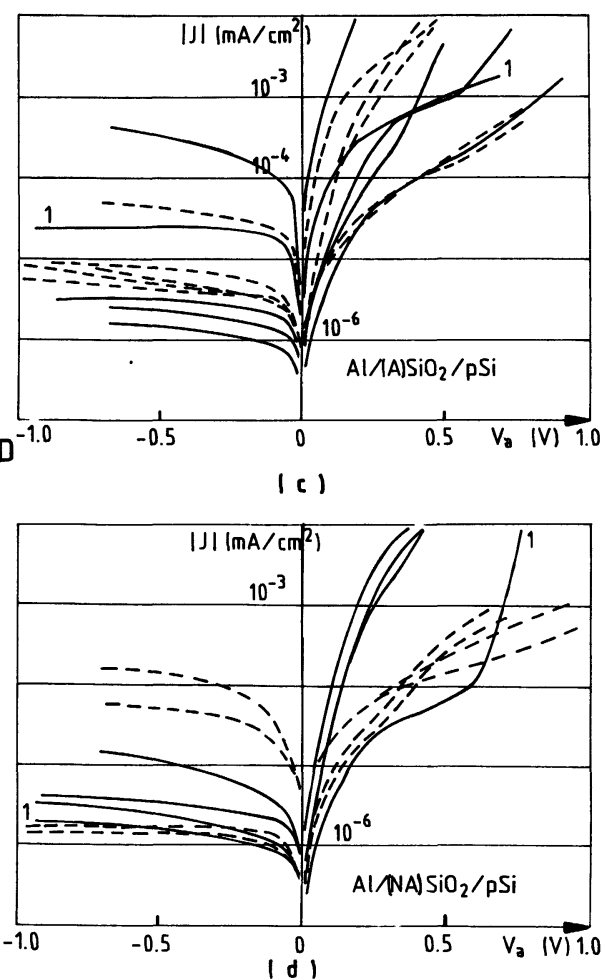

Fig. 3. - Experimentally observed dispersion of $J-V_{\mathrm{a}}$ characteristics for LPCVD (solid lines) and $\mathrm{LPO}_{2}$ (dashed lines) annealed or not devices on $n(a$ and $b)$ and $p\left(c\right.$ and d) type wafer $\left((\mathrm{A}) \mathrm{SiO}_{2}:\right.$ annealed $\mathrm{SiO}_{2},(\mathrm{NA}) \mathrm{SiO}_{2}:$ not annealed $\left.\mathrm{SiO}_{2}\right)$. 
case of annealed or not samples. The shapes of the curves are preserved (saturation effect for reverse bias, characteristics generally curved toward the voltage axis for forward bias). There are approximately two orders of magnitude of dispersion in the reverse characteristics at $-0.7 \mathrm{~V}$. The experimental dispersion of the $J(V)$ characteristics depends on the parameters mentioned in section 4.3.2 and mainly of $\delta, \chi$ (the tunnelling current is proportional to $\left.\exp \left(-\chi^{0.5} \delta\right)\right)$ and the density of the states.

Hysteresis on current-voltage characteristics has been studied. The $4140 \mathrm{~B}$ pA-meter mentioned in section 3 has a voltage source with a double staircase wave : output voltage changes step by step from start voltage to stop voltage. Successively, output voltage is returned to start voltage by same step voltage. The hold time at beginning and end of voltage ramp is fixed to $1 \mathrm{~s}$. The annealed LPCVD oxides on $\mathrm{n}$ type substrate do not show hysteresis. Generally for a step delay time of $10 \mathrm{~s}$ and $1 \mathrm{~s}$ there is no observable hysteresis. Slight displacements between the curve corresponding to an increasing voltage (from start to stop voltage) and the curve corresponding to a decreasing voltage are observed for short delay times $0.1 \mathrm{~s}$ and particularly $0.01 \mathrm{~s}$. This is due to time response of the circuit.

4.2 Characteristics ON p tyPe SUbSTRate. - Typical characteristics are represented in linear (range of $10^{-10} \mathrm{~A}$ ) and semilogarithmic plots in figures $2 \mathrm{c}$ and $\mathrm{d}$ respectively. The reverse characteristics have a tendency to present a saturation effect around a voltage of $-1 \mathrm{~V}$ (Fig. 2d), the density of current is in the range of $10^{-5} \mathrm{~mA} / \mathrm{cm}^{2}$.

Some forward characteristics exhibit a kind of plateau similar to that presented by Shewchun et al. [4] the current increases approximately exponentially with voltage for low voltage values then increases less rapidly, and at last starts to increase rapidly with voltage above $0.6 \mathrm{~V}$ (curve 1 in Fig. 2d). These authors $[4,5]$ explained this kind of plateau by considering the distribution of the external applied voltage between the oxide layer and the semiconductor, when the semiconductor surface goes from depletion to accumulation regime. This plateau effect is attenuated by the action of interface states.

The dispersion curves are shown in figures $3 \mathrm{c}$ and $\mathrm{d}$. The reverse characteristics show a saturation effect, we have approximately a dispersion of two orders of magnitude, the forward characteristics show often the kind of plateau mentioned above (curves 1 in Figs. $3 c$ and $d$ ).

Hysteresis on current-voltage characteristics has been studied. As in $\mathbf{n}$ type device slight displacements between the curve corresponding to an increasing voltage and the curve corresponding to a decreasing voltage are observed for short delay times of $0.1 \mathrm{~s}$ or $0.01 \mathrm{~s}$ (see section 4.1). No hysteresis is observable for delay times above $1 \mathrm{~s}$.

\section{3 Discussion.}

4.3.1 Comparison of MIS tunnel diodes on $\mathrm{n}$ and $\mathrm{p}$ type substrate. - As a general rule, there is at least an order of magnitude between the currents (forward or reverse) for the same bias range in MIS tunnel diodes on $\mathrm{n}$ and $\mathrm{p}$ type wafers (see Fig. 1). There are also some differences in the shape of the forward curves, the effect of " plateau " mentioned in section 4.2 appears only in devices on $\mathrm{p}$ type substrate significantly. We can note also that there is no important difference between the $I-V$ characteristics for the devices prepared by $\mathrm{LPO}_{2}$ and LPCVD technologies (see section 4.1).

It is known in the literature [4-7] that majority carriers dominate the tunnel current in tunnel diodes on $\mathrm{n}$ type substrate and that minority carriers dominate in $\mathrm{Al}-\mathrm{SiO}_{2}-\mathrm{pSi}$ structures. Indeed the $\mathrm{Al}-\mathrm{SiO}_{2}-\mathrm{pSi}$ structure has naturally a large metal-semiconductor barrier height $\Phi_{\mathrm{B}}$ as a result of the difference in work function between $\mathrm{Al}$ and $\mathrm{p}$ type $\mathrm{Si}$. This can explain the difference in the magnitude of currents in $n$ and $p$ type structure. The results on capacitance-voltage measurements presented further corroborate this analysis, we see indeed that the silicon surface is inverted for zero bias for $\mathrm{p}$ type structure and near accumulation for $n$ type.

We have quoted above, papers giving a detailed numerical and experimental analysis of MIS tunnel diodes on $\mathrm{p}$ wafer $[4,5]$. In the present work we use a simulation model $[1,8]$ developed for an $n$ type semiconductor, particularly to study the dispersion of $I-V$ characteristics on $\mathbf{n}$ type silicon. The results obtained using this model are presented in the next section (4.3.2).

\subsubsection{Modelling study connected to the dispersion of} I-V curves. - In MIS tunnel structures with a very thin oxide layer the mechanisms for current conduction are : tunnelling between the metal and the majority carrier energy band in the semiconductor, tunnelling between the minority carrier energy band, tunnelling between the metal and surface state levels (surface states act as recombination generation centres and provide additional tunnelling paths between the metal and the semiconductor). From these considerations, a simulation model for the working of MIS tunnel structures has been developed by the authors [1, 8]. In this model the usual differential equations describing the potential distribution and the transport of free carriers are replaced by a nonlinear algebric equation system : the numerical solution becomes easier and it needs shorter computation time. The modelling is carried out on Multics CII-HB67 computer. The actual continuous distribution obtained by $C / G(V, \omega)$ studies is replaced by discrete levels (here two), in order to simplify the simulation program and decrease the calculation time.

a) An acceptor-like level located near conduction band $\left(E_{\mathrm{c}}-E_{\mathrm{T}_{0}}\right.$ typical value $\left.0.3 \mathrm{eV}\right)$ having a density $N_{\text {so }}$ and an electrostatic and kinetic action [2], acting 
essentially on the forward characteristics and less on the reverse characteristics.

b) A donor-like level $E_{\mathrm{T}_{1}}$ located typically at the vicinity of the midgap having a density $N_{\mathrm{s}_{1}}$ and an electrostatic action [2], acting on the reverse characteristics and allowing us to simulate the threshold effect observed on the reverse characteristics.

The other important parameters of the modelling which enable to fit the experimental and theoretical curves are : the oxide thickness $\delta$ and the effective electron/hole affinities $\chi_{\mathrm{n}}, \chi_{\mathrm{p}}$.

It is not necessary to introduce a fixed charge in the numerical simulation. Indeed the interface state densities used, allow us to fit the experimental results and are consistent with the values obtained by experimental measurements $(C / G(V, \omega))$.

Typical modelling curves are shown in figures $4 a$ and $4 \mathrm{~b}$ for LPCVD and $\mathrm{LPO}_{2}$ devices respectively. We note that a satisfactory modelling can be found with only two single levels of interface states by simply varying the values of $\delta, \chi_{\mathrm{n}}, E_{\mathrm{T}_{0}}, E_{\mathrm{T}_{1}}, N_{\mathrm{s}_{0}}, N_{\mathrm{s}_{1}}$. We can remark (Figs. 4a and b) that the observed discrepancies between experimental and theoretical curves are due to the fact that our calculations are based on single level interface states which actually replace the continuous distribution.

We can discuss now the variation of modelling parameters. For example between the curves $\left(1^{\prime}\right)$ and $\left(3^{\prime}\right)$ of figure 4 a we have a variation of $J$ of two orders of magnitude (for $V_{\mathrm{a}}=-1 \mathrm{~V}$ ). By supposing that there is no dispersion of the typical oxide thickness value $(\delta=30 \AA)$, we find using our model a $\chi_{n}$ variation of $0.15 \mathrm{eV}, \mathrm{a} N_{\mathrm{s}_{0}}, N_{\mathrm{s}_{1}}$ variation of $9 \times 10^{11} \mathrm{~cm}^{-2}$ and $2.4 \times 10^{11} \mathrm{~cm}^{-2}$ respectively.

Between the curves $\left(1^{\prime}\right)$ and $\left(3^{\prime}\right)$ of figure $4 \mathrm{~b}$ we find in the conditions mentioned above a variation for $\chi_{\mathrm{n}}$ of $0.18 \mathrm{eV}$, for $N_{\mathrm{s}_{1}}$ of $1.8 \times 10^{11} \mathrm{~cm}^{-2}$ and no variation of $N_{\mathrm{s}_{0}}$. In conclusion with the assumption of constant oxide thickness, we can modelize experimental extreme curves of figure 4 with a variation of $\chi_{n}$ lower than $0.2 \mathrm{eV}$ and a variation of interface state density $\left(N_{\mathrm{s}_{0}}\right.$ or $\left.N_{\mathrm{s}_{1}}\right)$ lower than $9 \times 10^{11} \mathrm{~cm}^{-2}$. It may be noted that the variation of the current obtained by the simulation model are very sensitive particularly to the variations of $\chi$ and also to the variations of the state density of donor type $\left(N_{\mathrm{s}}\right)$ acting on the reverse characteristics (see above). The acceptor states $\left(N_{\mathrm{so}_{\mathrm{o}}}\right)$ acting on the forward characteristics play a less important role due to their energetical position with regard to the Fermi level. The accuracy is then not as good for the acceptor states $\left(N_{\mathrm{s}_{0}}\right)$ than for the donor states $\left(N_{\mathrm{s}_{1}}\right)$. The $\chi$ values determined by the modelization are consistent with those reported in the literature [9]. To our knowledge the physical reasons of the observed dispersion of $\chi$ values has not been studied in the literature.

On the contrary if we assume a possible thickness dispersion in the order of $2 \AA$ we can determine the values of the other parameters. Such thickness varia-
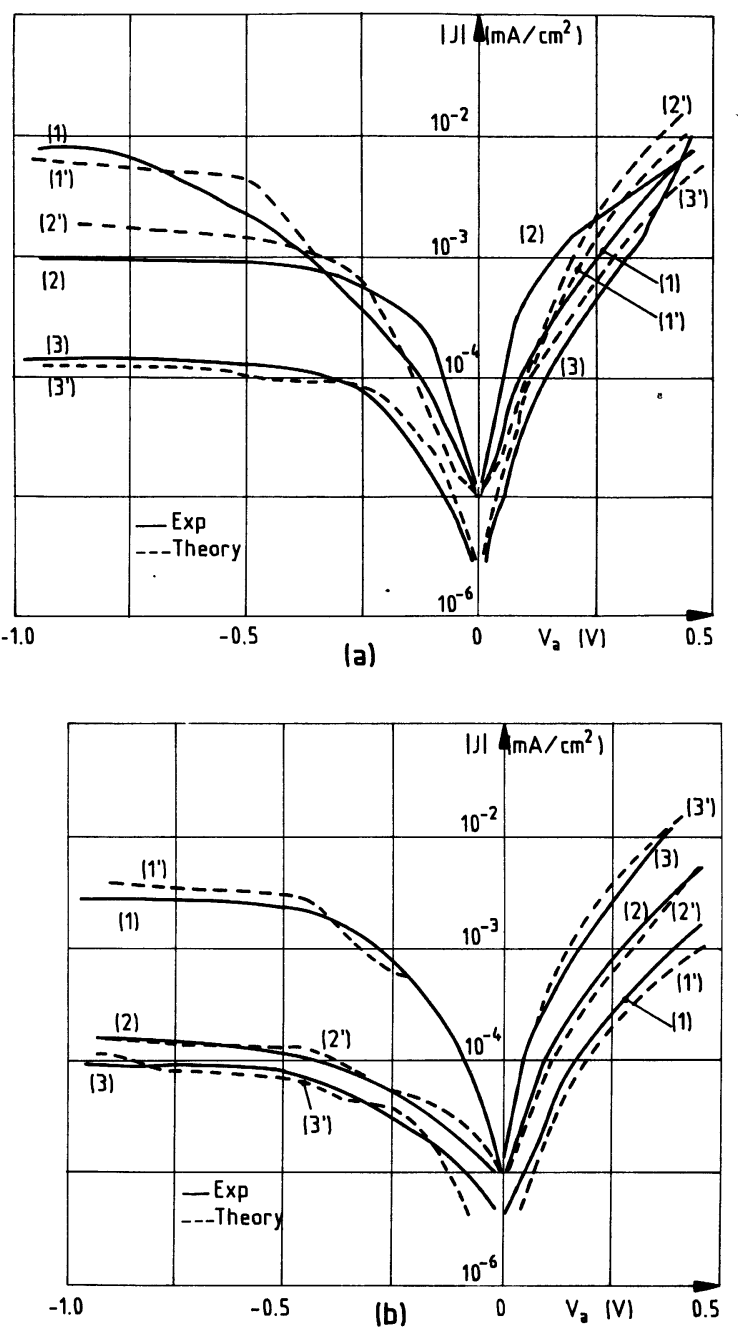

Fig. 4. - Fitting between experimental (solid lines) and theoretical (dashed lines) $J-V_{\mathrm{a}}$ curves for LPCVD (a) and $\mathrm{LPO}_{2}$ (b) devices on $\mathrm{n}$ type substrate. Parameter of the modelling : $\Phi_{\mathrm{ms}}=-0.15 \mathrm{eV}, C_{\mathrm{n}}=C_{\mathrm{p}}=2.5 \times 10^{-11} \mathrm{~m}^{3} \mathrm{~s}^{-1}$, $\delta=30 \AA$. Other parameters $\left(E_{\mathrm{T}_{0}}, E_{\mathrm{T}_{1}}, \chi\right.$ in $\mathrm{eV}, N_{\mathrm{s}_{0}}, N_{\mathrm{s}_{1}}$ $\mathrm{cm}^{-2}, V_{\mathrm{s}_{\mathrm{o}}}$ in $\mathrm{mV}$ ) :

Fig. 4a curve $1^{\prime} E_{\mathrm{T}_{0}}=0.3, E_{\mathrm{T}_{1}}=0.5, \chi=0.80$

$$
N_{\mathrm{s}_{0}}=10^{12}, N_{\mathrm{s}_{1}}=3 \times 10^{11}, V_{\mathrm{s}_{0}}=113
$$

curve $2^{\prime} E_{\mathrm{T}_{0}}=0.3, E_{\mathrm{T}_{1}}=0.5, \chi=0.80$

$N_{\mathrm{s}_{0}}=10^{12}, N_{\mathrm{s}_{1}}=6 \times 10^{10}, V_{\mathrm{s}_{0}}=23$

curve $3^{\prime} E_{\mathrm{T}_{0}}=0.3, E_{\mathrm{T}_{1}}=0.5, \chi=0.95$ $N_{\mathrm{s}_{0}}=10^{11}, N_{\mathrm{s}_{1}}=6 \times 10^{10}, V_{\mathrm{s}_{0}}=113$

Fig. $4 \mathrm{~b}$ curve $1^{\prime} E_{\mathrm{T}_{0}}=0.25, E_{\mathrm{T}_{1}}=0.45, \chi=0.82$

$N_{\mathrm{s}_{0}}=5 \times 10^{11}, N_{\mathrm{s}_{1}}=2.6 \times 10^{11}$,

$V_{\mathrm{s}_{0}}=77$

curve $2^{\prime} E_{\mathrm{T}_{0}}=0.25, E_{\mathrm{T}_{1}}=0.5, \chi=1.0$

$N_{\mathrm{s}_{0}}=5 \times 10^{11}, N_{\mathrm{s}_{1}}=8 \times 10^{10}$,

$V_{\mathrm{s}_{0}}=77$

curve $3^{\prime} E_{\mathrm{T}_{0}}=0.25, E_{\mathrm{T}_{1}}=0.5, \chi=1.0$

$N_{\mathrm{s}_{0}}=5 \times 10^{11}, N_{\mathrm{s}_{1}}=8 \times 10^{10}$,

$V_{\mathrm{s}_{0}}=77$.

tion could corresponds to the insulating layer inhomogeneities on the wafer. These calculations were carried out using as an example the curve 1 of the figure $4 a$. 
We find so :

- For $\delta=30 \AA$

$N_{\mathrm{s}_{0}}=10^{12} \mathrm{~cm}^{-2} \quad N_{\mathrm{s}_{1}}=3 \times 10^{11} \mathrm{~cm}^{-2} \quad V_{\mathrm{s}_{0}}=113 \mathrm{mV}$

- For $\delta=28 \AA$

$N_{\mathrm{s}_{0}}=10^{12} \mathrm{~cm}^{-2} \quad N_{\mathrm{s}_{1}}=5 \times 10^{11} \mathrm{~cm}^{-2} \quad V_{\mathrm{s}_{0}}=32 \mathrm{mV}$.

Among these above two possibilities we can choose the first one which gives the $V_{\mathrm{s}_{0}}$ value in accordance with the capacitance measurement for this sample (section 5). So with this reasoning the fluctuations of the thickness are not involved.

\section{Capacitance and conductance-voltage characteris-} tics.

5. 1 EXPERIMENTAL RESULTS ON $C$ AND $G-V$ vs. BIAS AT DIFFERENT FREQUENCIES. - The curves of figure 5 (solid lines) present the variations of capacitance vs. bias for devices on $\mathrm{n}$ and $\mathrm{p}$ type wafers at several frequencies of measurement $\left(C_{\mathrm{m}}\right.$ in linear scale).

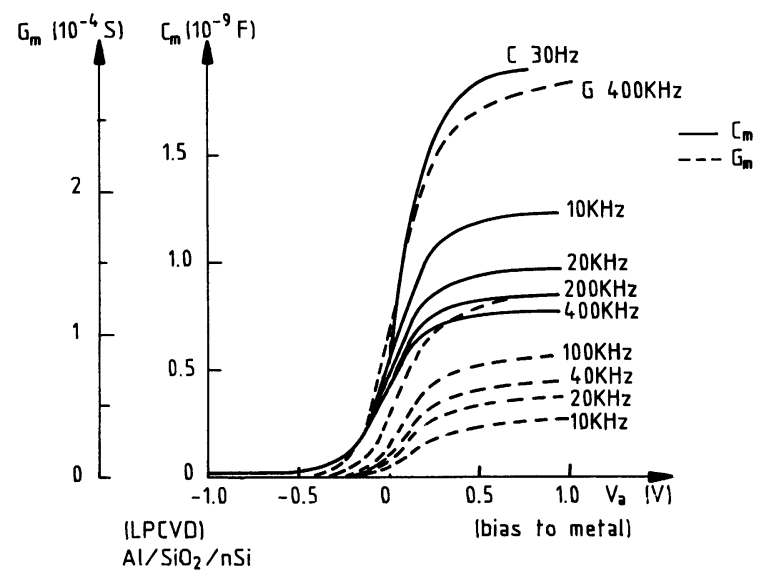

(a)

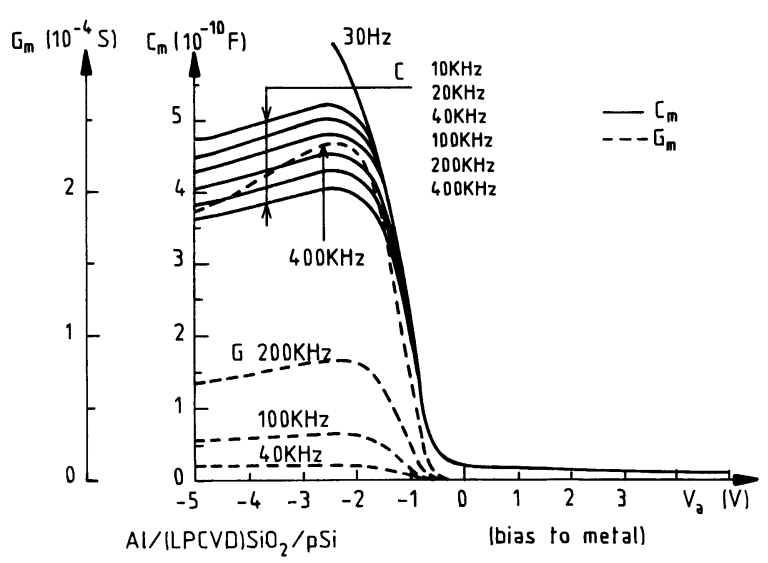

(b)

Fig. 5. - Measured capacitance (solid lines) and conductance (dashed lines) versus applied voltage characteristics for devices on $\mathrm{n}(\mathrm{a})$ and $\mathrm{p}(\mathrm{b})$ wafer (linear plot for $C_{\mathrm{m}}$ and $G_{\mathrm{m}}$ ).
For devices on $\mathrm{n}$ type substrate (curves 5a) we observe, in accumulation, plateau values $C_{\mathrm{ma}}$, which correspond to the $C_{\mathrm{ox}}$ value (in the order of $1900 \mathrm{pF}$ ) only at low frequencies (here $30 \mathrm{~Hz}$ ). For higher frequencies the contact resistance $R_{\mathrm{s}}$ of the samples provokes a decrease of the $C_{\mathrm{ma}}$ values [10] (see equivalent circuits of Figs. 7a and b) :

$$
C_{\mathrm{ma}}=\frac{C_{\mathrm{ox}}}{1+R_{\mathrm{s}}^{2} C_{\mathrm{ox}}^{2} \omega^{2}}\left(\text { valid if } \frac{1}{R_{\mathrm{s}}} \gg G_{\mathrm{T}}\right) .
$$

This relation permits to evaluate $R_{\mathrm{s}}$. We found $R_{\mathrm{s}}$ around $250 \Omega$.

For devices on $p$ type substrate the accumulation is obtained for larger voltage value than in the case of $n$ type device (Fig. 5b). It is obtained in accumulation region plateau values of $C_{\mathrm{ma}}$ lightly increasing with bias $V_{\mathrm{a}}$. The series-resistance is found to be around $400 \Omega$ in this case.

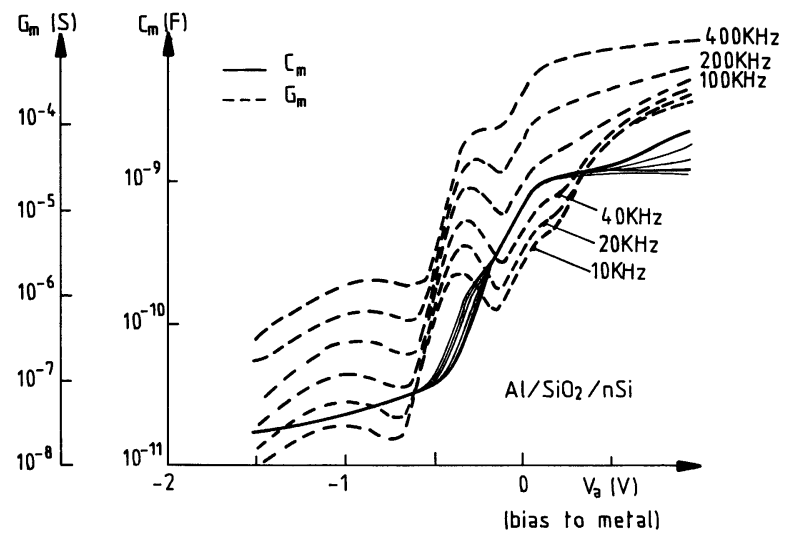

(a)

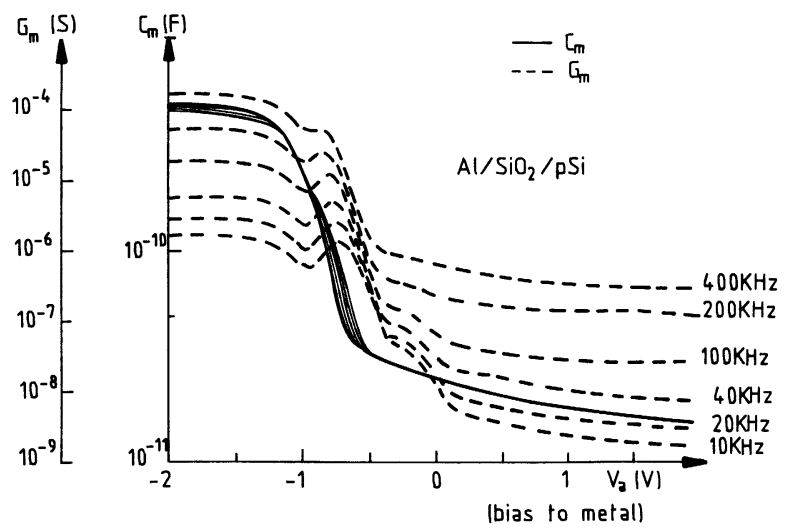

(b)

Fig. 6. - Measured capacitance (solid lines) and conductance (dashed lines) versus applied voltage characteristics for devices on $\mathrm{n}(\mathrm{a})$ and $\mathrm{p}(\mathrm{b})$ wafer (logarithmic plot for $C_{\mathrm{m}}$ and $\left.G_{m}\right)$. 


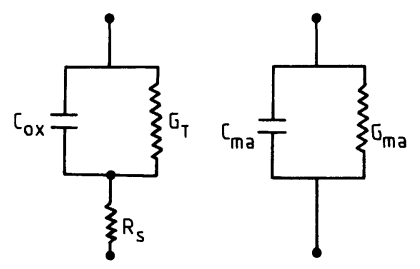

(a)

(b)

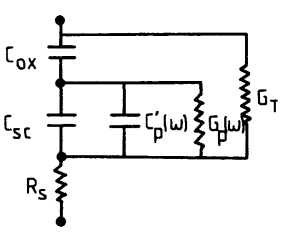

(c)

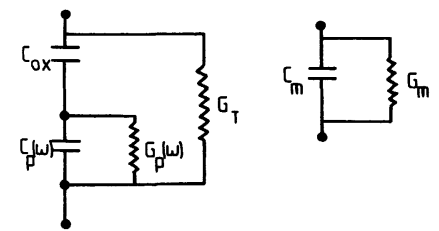

(d)
Fig. 7. - Equivalent circuit of MIS tunnel diodes for seriesresistance determination in accumulation ( $a$ and $b$ ) and for $N_{\text {ss }}$ determination (c and d).

Accumulation begins at around $-1 \mathrm{~V}$ in $\mathrm{p}$ type devices and $0.1 \mathrm{~V}$ in $\mathrm{n}$ type. These results are in agreement with the semiconductor surface regime at 0 voltage bias : inversion for $p$ type devices and depletion-accumulation for $\mathrm{n}$ type devices (see section 4.3.1).

The curves of figure 5 (dashed lines) present the variations of the conductance vs. bias voltage with $G_{m}$ in linear scale for the same devices as previously. The losses increase with the frequency [11] according to :

$$
G_{\mathrm{ma}}=\frac{G_{\mathrm{T}}+R_{\mathrm{s}} C_{\mathrm{ox}}^{2} \omega^{2}}{1+R_{\mathrm{s}}^{2} C_{\mathrm{ox}}^{2} \omega^{2}}\left(\text { valid if } \frac{1}{R_{\mathrm{s}}} \gg G_{\mathrm{T}}\right) .
$$

The peaks in $G_{\mathrm{m}}-V_{\mathrm{a}}$ curves in the depletion region are only observed with $G_{\mathrm{m}}$ in logarithmic plot. Typical example is shown in figures $6 a$ and $b$.

5.2 Evaluation of $N_{\mathrm{ss}}$ AND $V_{\mathrm{s}}$. - The conductance method of Nicollian and Goetzberger [1, 11-13] is suitable for the determination of interface state density $N_{\text {ss }}$ in MIS structure with very thin oxide layer. The necessary equivalent circuits of the MIS diode for this evaluation are shown in figures $7 \mathrm{c}$ and $\mathrm{d}$. The $\mathrm{n}$ devices are in depletion in low reverse bias (Fig. 5a), so the evaluation of $N_{\mathrm{ss}}$ is possible. The p devices are in inversion in reverse bias (Fig. 5b), and so we have not determined the interface state density in that case.

We found $N_{\mathrm{ss}}$ values typically $5 \times 10^{11} \mathrm{~cm}^{-2} \mathrm{eV}^{-1}$ near the midgap for annealed LPCVD $\mathrm{n}$ devices and slightly higher for other $\mathrm{n}$ devices (around $10^{12} \mathrm{~cm}^{-2}$ $\mathrm{eV}^{-1}$ near the midgap). These values are consistent with those used in modelling section (4.3.2).

The determination of surface potential has been carried out with Berglund integral [11] on low frequency $C-V$ characteristics $(30 \mathrm{~Hz})$.
The $V_{\mathrm{s}_{0}}$ value (surface potential at $0 \mathrm{~V}$ ) have been evaluated by HF measurement [1]. We have found generally a positive value, depending on the samples between $50 \mathrm{mV}$ and $150 \mathrm{mV}$ for $\mathrm{n}$ devices and about $600 \mathrm{mV}$ and $800 \mathrm{mV}$ for $\mathrm{p}$ type devices.

Finally we have reported on figure 8 the experimental (solid lines) curves $V_{\mathrm{s}} v$ s. $V_{\mathrm{a}}$ for two samples (on $\mathrm{n}$ and $\mathrm{p}$ type substrate). The dashed line represents, for example, a theoretical $V_{\mathrm{s}} v s$. $V_{\mathrm{a}}$ curve obtained by the simulation program of section 4.3.2. The agreement between experimental and theoretical results is generally satisfactory except for some not annealed LPCVD $\mathrm{n}$ devices which are in accumulation for zero volt bias.

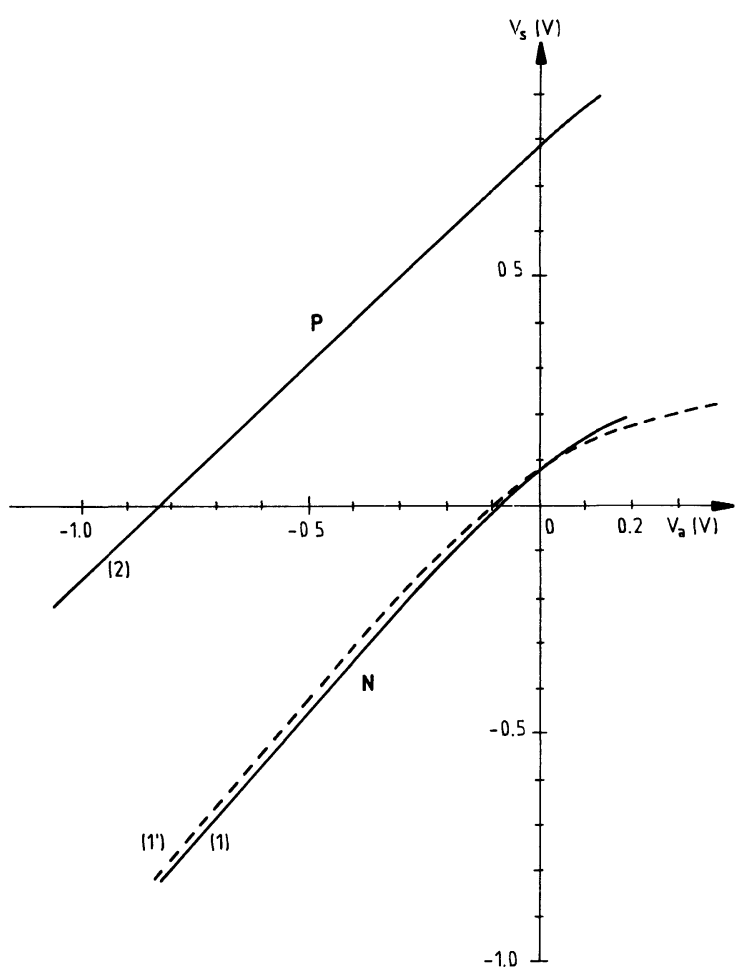

Fig. 8. - Semiconductor surface potential $v s$. applied voltage $V_{\mathrm{a}}$ for a device on $\mathrm{n}$ type wafer : experimental (1) and theoretical (1') and for a device on p type wafer (2).

\section{Conclusion.}

In this paper $\mathrm{Al}_{-} \mathrm{SiO}_{2}-\mathrm{Si}$ tunnel structures with thin oxide layers ( $30 \AA)$ on $n$ and $p$ type wafers have been studied using measurements based on a microcomputer controlled system.

Interesting results may be deduced from the modelling of experimental $I-V$ curves. The dispersion of these characteristics on the same wafer allow us to deduce dispersion of the most important physical parameters. 
Thus, we have shown with the assumption of constant oxide thickness (typical value $30 \AA$ ) that the extreme experimental $I-V$ curves can be fitted with an electronic affinity variation lower than $0.2 \mathrm{eV}$ and an interface states density variation lower than $9 \times$ $10^{11} \mathrm{~cm}^{-2}$.
This study is able to provide very useful information about the dispersion of the most important physical parameters of the $\mathrm{Si}_{1}-\mathrm{SiO}_{2}$ interface for very thin insulator layers. It would so be possible to improve the technological process in order to obtain good quality thin oxide layers.

\section{References}

[1] Pananakakis, G., Kamarinos, G., El-Sayed, M. and LE GoASCOZ, V., Solid State Electron. 26 (1983) 415.

[2] Pananakakis, G., Kamarinos, G. and Viktorovitch, P., Revue Phys. Appl. 14 (1979) 639.

[3] Jaouen, H., Bouro, L., Pananakakis, G., Comm. at applied Modelling and Simulation, Paris-Sud, 1-3 July 1982.

[4] Shewchun, J., Green, M. A. and KIng, F. D., Solid State Electron. 17 (1974) 563.

[5] Green, M. A., King, F. D. and Shewchun, J., Solid State Electron. 17 (1974) 551.

[6] Card, H. C., Infos 79, Proceeding of Inst. Phys. Conf. ser. 50 (1979) 140.
[7] Tarr, N. G., Pulfrey, D. L. and Camporese, D. S., IEEE Trans. E.D. ED 30 (1983) 1760.

[8] Pananakakis, G., Thesis DE, INP Grenoble (1979).

[9] CARD, H. C., Solid State Electron. 22 (1979) 809.

[10] Nicollian, E. H. and Brews, J. R., MOS Physics and Technology (Wiley-Interscience, New York) 1982.

[11] Nicollian, E. H., GoetzBerger, A., The Bell System Techn. J. 46 (1967) 1055.

[12] Sze, S. M., Physics of Semiconductors Devices (WileyInterscience, New York) 1981.

[13] KAR, S., DAHLKE, W. E., Solid State Electron. 15 (1972) 221. 